\title{
IPCC's ritual on global warming
}

If the threat of global warming is serious (which cannot be denied), it deserves more seemly ways of making authoritative opinion public than that followed at last week's meeting at Maastricht.

So the greenhouse effect is real, then? That will be the first reaction of those who read of last week's meeting at Maastricht of the Intergovernmental Panel on Climate Change (IPCC), which is preparing its second assessment of the extent to which greenhouse gases in the atmosphere will affect the Earth's radiation balance. By all accounts (but see page 274), carbon dioxide has continued to accumulate, but only half as quickly as carbon dioxide is generated by the combustion of fuel. (The remainder is probably locked up in the biosphere, or dissolved in the oceans, temporarily or otherwise.) And while the concentration of methane in the atmosphere is increasing at a decelerating rate, IPCC says that, molecule for molecule, its effect on climate is greater than previously allowed. But interested readers (of whom there are in principle about 5 billion) will have to wait until the secretariat has taken account of last week's discussion, and until Cambridge University Press has turned the outcome into type, before they will be able to weight the quality of the discussion.

This is a rotten way to conduct international business, the more so because literally everyone in the world will eventually be affected by it. Last week's reports from Maastricht suggest that the goal of restraining emissions of carbon dioxide below those of 1990 (the European Union's collective goal) will be insufficient even to prevent a further doubling of carbon dioxide concentration in the atmosphere. That has been on the cards from the outset, but the apportionment of allowable emissions among the potential claimants on them will be a much more difficult task than the negotiation of the Convention on Climate Change at Rio de Janeiro two years ago, where it must have seemed to many that a mere signature could prevent climatic deterioration. If IPCC is serious (and there is no reason to believe otherwise), it should now be doing everything it can to make the further agreements that will be necessary winnable.

Communication by press release and "Executive Summary" (a euphemism for sound-bites directed at those who do not read) is no way in which to do that. What the world needs is a measured critical review of the literature on greenhouse gases and their effects on climate, perhaps covering the period since the last assessment in 1990. That is exactly how the UN Scientific Committee on Energetic Atomic Radiation (UNSCEAR) has conducted its business since its creation at the instance of the government of India in the 1950s. Such a framework is an entirely suitable vehicle for considered opinions on the significance of emerging trends, and indeed is particularly well-suited to the consideration of the global warming problem, where uncertainties now extant are likely to be removed as the years pass. A useful format for IPCC's reports would be a listing of the continuing uncertainties and a periodic discussion of the extent to which they had been removed.

On this occasion, the press release put out from Maastricht declares that "the scientific consensus established in 1990 by the IPCC on climate science still holds". What does that mean? Certainly not that IPCC or its sponsoring agencies, the UN Environmental Programme and the World Meteorological Organization, were the first to define the global warming issue (which was almost the single-handed creation of Dr Roger Revelle at Harvard University). Unanimity? Nobody denies that carbon dioxide is a greenhouse gas, but argument persists in the research community about the effects on climate. To be persuasive, IPCC must show that it has given these issues the respectful considerations their origins command. Sadly, we shall not know for some time whether that essential obligation has been discharged.

\section{Discoveries for Africa}

Africa deserves a big share of the pride in early hominid discoveries.

THE interest of the accounts on pages 306-312 and 330-333 of the latest australopithecine species to be recovered from Ethiopia is unlikely to be overlooked. With an age estimated at 4.4 million years, Australopithecus ramidus is almost a million years older than $A$. afarensis and that much closer to the probable divergence of the hominid line from that of the Great Apes, estimated by molecular cladists at about 4-6 million years ago. That means that the most conspicuous gap in the pre-human fossil record has been filled even though, as always, the need for further specimens to yield more detail will remain.

Interest and importance apart, it is important that a few temptations should be avoided. The similarity of $A$. ramidus with the chimpanzee, rather than the gorilla, is remarked on by the authors of the new discovery as well as by Dr Bernard Wood (see page 280). That will lead many to conclude that Pan, the chimpanzee, was the closest living relative to the early hominids. But that is inference only, absent a better understanding than at present of the course of evolution of 